\title{
POLÍTICAS GOVERNAMENTAIS PARA A EDUCAÇÃo BÁSICA NA PARAÍbA: A PRIVATIZAÇÃO COMO ESTRATÉGIA DE HEGEMONIA
}

\author{
POLÍTICAS GUBERNAMENTALES PARA LA EDUCACIÓN BÁSICA EN PARAÍBA: \\ LA PRIVATIZACIÓN COMO ESTRATEGIA DE LA HEGEMONIA
}

\author{
GOVERNMENT POLICIES FOR BASIC EDUCATION IN PARAÍBA: \\ PRIVATIZATION AS A STRATEGY OF HEGEMONY
}

\author{
Antônio Lisboa Leitão de SOUZA ${ }^{1}$
}

RESUMO: O texto analisa algumas estratégias de políticas públicas para a educação escolar adotadas por governos da Paraíba, a partir dos anos 2000, contextualizando-as sobretudo a partir da reforma do aparelho estatal brasileiro na década de 1990. Destaca a centralidade política da "lei das parcerias", em 2004, quando governos estaduais ampliaram e diversificaram a perspectiva privatizante na gestão pública, com base na racionalidade gerencial, eficiência administrativa, rigor orçamentário, enxugamento da máquina pública e consequente fortalecimento de instituições privadas, seja na elaboração, na execução de programas de responsabilidade dos governos de turno. Também situa o PNE (lei 10.172/2001) como fator de favorecimento ideológico de estratégias privatizantes. A partir de análise preliminar de "parcerias" efetivadas pelo governo estadual, mostrar como essa estratégia constitui exemplo de construção de hegemonia, no sentido gramsciano, com fins a se naturalizar a defesa do privado como o referencial de eficiência e qualidade.

PALAVRAS-CHAVE: Educação básica. Privatização. Parcerias. Hegemonia. Paraíba.

ABSTRACT: The text analyzes some strategies of public policies for the school education adopted by the governments of Paraiba, starting from the years 2000, contextualizing them mainly from the reform of the Brazilian state apparatus in the decade of 1990. It emphasizes the political centrality of the "low of partnership", in 2004, when state governments expanded and diversified the privatization perspective in public management, based on management rationality, administrative efficiency, budgetary rigor, wipe out the public machine and the consequent strengthening of private institutions, whether in the development, in the execution of programs of responsibility of the governments on duty. It also places PNE (Law 10.172/ 2001) as a factor favoring ideological privatization strategies. End from the preliminary analysis of "partnership" made by the state government, shows how this strategy constitutes an example of building hegemony, in the Gramscian sense, with the aim of naturalizing the defense of the private as the benchmark of efficiency and quality.

KEYWORDS: Basic Education. Privatization. Partnership. The hegemony. Paraíba.

${ }^{1}$ Universidade Federal de Campina Grande (UFCG), Campina Grande - PB - Brasil. Professor Associado e membro permanente do Programa de Pós-Graduação em Educação/PPGEd-UAED-CH, onde orienta estudos e pesquisas na Linha História, Política e Gestão da Educação. Membro do Comitê Científico da Anped. ORCID: <https://orcid.org/0000-0002-4234-4261>. E-mail: lisboaleitao@uol.com.br

RPGE- Revista on line de Política e Gestão Educacional, Araraquara, v. 22, n. esp. 3, p. 1340-1354, dez., 2018 ISSN: 1519-9029. DOI: 10.22633/rpge.v22iesp3.12017 
Resumen: El texto analiza algunas estrategias de políticas públicas para la educación escolar adoptadas por gobiernos de Paraíba, a partir de los años 2000, contextualizándolas sobre todo a partir de la reforma del aparato estatal brasileño en la década de 1990. Destaca la centralidad politica de la "ley de las alianzas", en 2004, cuando gobiernos estatales ampliaron y diversificaron la perspectiva privatizadora en la gestión pública, con base en la racionalidad gerencial, eficiencia administrativa, rigor presupuestario, enjugación de la máquina pública y consecuente fortalecimiento de instituciones privadas, sea en la elaboración, en la ejecución de programas de. responsabilidad de los gobiernos de turno. También sitúa al PNE (ley 10.172 / 2001) como factor de favorecimiento ideológico de estrategias privatizantes. E a partir del análisis preliminar de las alianzas realizadas por el gobierno estadual, mostra cómo esta estrategia constituye un ejemplo de construcción de hegemonía, en el sentido gramsciano, con fines a naturalizarse la defensa de lo privado como el referencial de eficiencia y calidad.

PALABRAS CLAVE: Educación Básica. La privatización. Alianzas. La hegemonía. Paraíba.

\section{$O$ contexto}

A adequação do estado da Paraíba à racionalidade administrativa vigente, que tem como centro, além da enxugamento da máquina estatal, os princípios mercadológicos do gerencialismo eficiente (ou Nova Gestão Pública), do arrocho fiscal e do estabelecimento de parcerias com a iniciativa privada como modus operandi estratégico para execução de suas ações e metas, foi um processo que se iniciou ainda nos anos de 1990, tendo se aprofundado ao longo da década seguinte, adquirindo contornos mais definidos, principalmente com a aprovação da Lei federal no 11.079/2004, a chamada "lei das parcerias", sancionada em 30 de dezembro do mesmo ano pelo então presidente Lula da Silva. Com esta lei, institucionalizouse no país as normas gerais para licitação e contratação de parcerias público-privada no âmbito dos poderes da União, dos estados, do Distrito Federal e dos municípios. Além disso, imprimiu-se mais clareza e robustez ao aparato jurídico-normativo e político-ideológico da reforma do aparelho estatal brasileiro, iniciada na década anterior pelo governo Fernando Henrique Cardoso. Sobre esse processo mais amplo, a vasta produção bibliográfica possibilita diferentes leituras, tais como Pereira (1997), Abrucio (2007), De Angelis (2015), dentre tantos outros.

No intento de modernizar a máquina estatal e regulamentar a implementação da legislação federal no âmbito estadual, adequando-a à nova racionalidade governamental e, portanto, colocando o estado em sintonia mais fina com a política mais ampla, induzida pelo governo federal, o governo da Paraíba aprovou a Lei $\mathrm{n}^{\circ} 8.486 / 2008$, a partir da qual ficou ainda mais explicitada a lógica gerencial, bem como os processos de privatização da coisa 
pública, não só por meio de "parcerias" na execução de grandes obras estruturantes, mas, também, a partir de medidas mais sutis, em setores onde aparentemente se objetiva apenas "maior eficiência" administrativa e de gestão da própria máquina pública. Nesse sentido, diferentes áreas sociais foram alvo dessa nova racionalidade, como podemos perceber na educação.

A título de exemplo de como a política implementada nacionalmente induziu práticas semelhantes nas esferas estaduais, há um dado sobre o estado da Paraíba que corrobora essa perspectiva de alinhamento gerencial e viés privatizante na gestão pública. Antes mesmo da referida lei estadual $\mathrm{n}^{\circ} 8.486 / 2008$, quando o estado era governado por Cássio Cunha Lima (PSDB), já fazia parte da política governamental estadual o estabelecimento de parcerias com empresas privadas ou suas fundações, assim como se fazia com outras entidades públicas, na perspectiva de complementação da ação estatal na área educacional. É isto que se pode observar no texto do anexo à Lei $n^{\circ}$ 8.043, de 30.06.2006, que aprovou o Plano Estadual de Educação, tendo sido publicado no Diário Oficial do estado nos seguintes termos:

[...] No caso das empresas privadas, percebe-se, ainda que de forma incipiente, um crescimento do apoio e do incentivo ao poder público, na perspectiva das responsabilidades sociais e éticas das empresas para com a população excluída deste país. Vem ganhando contornos mais ampliados e adesões diferenciadas a compreensão de que não importa apenas o lucro para a empresa, importa, também, contribuir para o desenvolvimento justo e igualitário da nação brasileira e, de forma particular, do Estado da Paraíba. Avanços - No caso específico da Paraíba, podem ser registradas as seguintes ações de colaboração entre os sistemas de ensino, bem como com a sociedade civil, por meio de parcerias: a) Com a União [...]; b) Com os Municípios [...]; c) Com as instituições de ensino superior e médio [...]; d) Com Empresas Privadas e/ou suas Fundações: Institutos Instituto Ayrton Senna: Programas de correção do fluxo escolar - Se Liga Paraíba e Acelera Paraíba. Coca-Cola: Projeto Coca-Cola de Valorização do Jovem Estudante e implantação de um Centro de Inclusão Digital em João Pessoa. Fundação Banco do Brasil: instalação de telecentros nas escolas estaduais e municipais e o Cozinha Brasil (capacitação de merendeiras). Microsoft: Programa Aluno Monitor, Sua Escola a 2000 por hora, Fresh Start (repasse de licenças de softwares para os laboratórios doados) e o School Agreement (fornecimento de produtos Microsoft com preços subsidiados). Teatro Escola do Ballet Bolshoi do Brasil: formação profissional para o ballet. Instituto Alpargatas: Projeto Educação por meio do Esporte. Instituto Telemar: instalação de internet nas escolas públicas; e) Entidades da sociedade civil UNICEF - Pacto do Semi-Árido e Projeto de Construção dos Planos Municipais de Educação. Aliança Francesa - curso de francês para alunos da rede estadual, em Campina Grande e João Pessoa [...]. SESC Projeto Cinema vai à Escola. SESI, SENAR, Projeto Escola Zé Peão. RELEJA e Sal da Terra - Programa de Alfabetização de Adultos. (PARAÍBA, D.O.E de 01.07.2006, p. 20-21. Grifos nossos) 
Trata-se, pois, de uma práxis política inserida no contexto mais amplo de neoliberalização do Estado e da sociedade, sempre no sentido do fortalecimento da perspectiva privatizante, ideia segundo a qual o setor privado seria o guardião das competências e do saber fazer, inclusive na área educacional, em detrimento do público estatal, de suas competências e saberes, no caso específico, na gestão e no fazer pedagógico educacional escolar. Grosso modo, os governos estaduais e municipais adotaram essa perspectiva gerencial de "parcerias" na máquina pública.

$\mathrm{Na}$ área educacional, a necessidade de elaboração de seus respectivos planos de educação, induzidos pela aprovação do Plano Nacional de Educação (Lei no 10.172, de 09.01.2001), serviu, ao nosso ver, como elemento de justificativa política e de convencimento ideológico, por parte dos governos de turno, quanto a suposta necessidade de se buscar "apoio" do setor privado para a realização e alcance das estratégias e metas educacionais definidas nos Planos educacionais locais.

\section{A estratégia}

Nesse sentido, dando continuidade a essa perspectiva administrativa do governo anterior (PSDB) e embalado por um ambiente político ideológico favorável, o governo Ricardo Coutinho (PSB), sobretudo em seu segundo mandato consecutivo (2015-2018), não hesitou na implementação de políticas neoliberalizantes, de aprofundamento da racionalidade administrativa vigente, expressas, por um lado, no controle orçamentário-fiscal e, por outro, na abertura de espaços para fortalecimento do setor privado como partícipe direto e sujeito referente no aprimoramento da gestão pública, tanto na elaboração quanto execução das políticas governamentais.

O ambiente favorável a que me refiro diz respeito, por um lado, ao fato de, em diferentes pesquisas realizadas pelo Instituto Ibope, por exemplo, em períodos e anos consecutivos, desde 2013 [algumas por encomenda da Confederação Nacional das IndústriasCNI, como a de 27/11 a 02/12/2013, publicada em diferentes jornais (ex.: Jornal MaisPB, disponível em: <www.maispb.com.br>), e outra publicada no jornal Estado de São Paulo, em 05/09/2016], o governador da Paraíba (Ricardo Coutinho) ter figurado dentre os melhores avaliados do país (na ótica do mercado, óbvio!), comparativamente aos demais governos estaduais, haja vista sua política de controle fiscal, de equilíbrio das contas públicas e de 
parcerias com a inciativa privada, o que era considerado pela grande mídia, especialmente pelo sistema Globo, como 'bem sucedida'.

Por outro lado, o contexto de crise político-econômica que se instaurou no país a partir do golpe de 2016, com o processo de impedimento da ex-presidente Dilma Rousseff, e a decorrente política draconiana de arrocho fiscal, instituída mediante aprovação da Emenda Constitucional $\mathrm{n}^{\circ}$ 95, de 15 de dezembro de 2016, pelo governo Michel Temer, resultou em maiores dificuldades de execução orçamentária pelos governos de turno. E isso forja uma política de adequação ainda mais rigorosa na gestão pública, sobretudo no que diz respeito às demandas das áreas sociais em relação aos limites ditados pela área econômica do governo federal.

Do ponto de vista do discurso oficial, portanto, como numa relação de chantagem com os governos locais, esse cenário deveria servir de exemplo e justificativa para o aprofundamento do controle administrativo, de enxugamento da máquina pública, de eficiência na gestão orçamentária, de eficácia no alcance de metas, condição sine qua non para que eventuais apoios ou supostos benefícios fiscais, por parte do governo central, pudessem ser pautados e/ou concedidos aos governos locais. Além disso, ainda na perspectiva ideológica oficial, impunha-se aos governantes a abertura de novas práticas e possibilidades de atuação empresarial, não só intensificando ou consolidando os setores públicos estatais onde ela já existia, mas suscitando abertura de novos espaços de atuação privada, forma esta que poderia resultar numa suposta dinamização da economia, na geração de postos de trabalho e, portanto, na superação da propalada "crise" econômica.

Fortalecer o mercado e tornar o estado menor e mais eficiente em sua gestão, portanto, pareciam as estratégias comuns e "salvadoras da pátria" no referido contexto de "crise". Foi, então, nesse cenário que se ampliaram e se intensificaram as estratégias de privatização, não só nas áreas de infraestrutura, também nas áreas sociais, destacadamente na dimensão da gestão pública. Todavia, isto não significa que as áreas, instituições ou serviços até então de responsabilidade direta do estado tenham sido entregues, vendidas ou concedidas à iniciativa privada. Ao contrário, trata-se, grosso modo, de contratos de prestação de serviços e/ou de convênios celebrados entre o estado e organizações privadas, com diferentes origens quanto ao setor econômico, distintos perfis e áreas de atuação.

No setor educacional público, por exemplo, é possível identificar organizações as mais variadas, algumas ligadas ao capital financeiro [ex. Fundação Itaú Social, Fundação Bradesco, Fundação Banco do Brasil], outras ao capital industrial [ex. Fundação Alpargatas, Fundação Lemann], outras à áreas de tecnologia, comunicação e informações [ex. Fundação Roberto 
Marinho, Google of Education], outras ainda sem uma origem claramente ligada ao setor produtivo nem especulativo, mas inequivocamente atuando na defesa dos mesmos interesses, tais como a Fundação Ayrton Senna, com programas amplamente presentes em redes e sistemas públicos de ensino no país. São todas, portanto, organizações da sociedade civil, corporativas em sua identificação, privadas em sua natureza jurídica, em seus fins e em sua essência.

No que diz respeito ao leque de atuação dessas organizações e ao 'cardápio' ou portfólio de ações com que se apresentam ou nas quais se lançam com fins ao planejamento e/ou execução de programas governamentais, de políticas públicas, impressionam o ecletismo de suas iniciativas e o poder de atração e de 'convencimento' que exercem sobre os governantes de turno, no que diz respeito ao know how ou expertise de suas equipes, a eficácia de seus produtos e sua adequação genérica ao conjunto dos problemas ou desafios identificados no setor público, por parte dos próprios governos, independente da realidade social, como sendo as áreas de maior urgência de enfrentamento por parte do poder público. Assim, considerando que a capacidade de ação do estado estaria esvaziada, obsoleta, atrasada, inadequada ou mesmo incompetente para os "novos desafios", o propalado potencial de eficiência dessas organizações privadas, com seu ecletismo de 'saberes e competências', encaixa-se no argumento oficial, segundo o qual, pelos argumentos com que se apresentam tais empresas, já estariam justificadas, por si só, as novas estratégias governamentais de adoção de "parcerias" com esses setores e organizações no âmbito da gestão pública, haja vista a busca por uma suposta maior eficiência. E este caminho é de mão única, apresentado pelos próprios agentes públicos como 'sem alternativas'.

Nessa perspectiva, e centrada numa forte retórica de amplo alcance social, torna-se muito clara a política de fortalecimento e de potencialização do próprio mercado, via de regra em detrimento da presença e atuação direta do próprio aparelho estatal, do esvaziamento de suas competências, de seu know how construído em determinadas áreas. Essa deliberada redefinição de suas responsabilidades, por parte do estado, fomenta um gradativo referencial cultural no imaginário social, segundo o qual o mercado seria o guardião das competências, da eficiência administrativa e da qualidade no que realiza. O oposto disso seria a percepção que se alimenta acerca dos serviços prestados pelo estado, senão a identificação de sua própria ineficiência, mas devendo ser entendida como parte da mesma estratégia retórica.

Numa linguagem metafórica de inspiração nietzschiana, o ambiente político neoliberal forja esse novo demiurgo da eficiência e eficácia administrativas - o mercado -, que se reveste de uma áurea pública e um falacioso interesse social, confundindo-se com o que seria 
o próprio 'estado em ação', no sentido gramsciano. A rigor, trata-se de um processo que corresponde ao que o próprio Gramsci (2000) identifica como sendo o 'estado ampliado', de cuja ação fazem parte setores organizados, aparelhos privados de hegemonia, por meio das quais são elaboradas e/ou difundidas as ideologias que se pretendem dominantes na direção da sociedade política, que é o próprio Estado.

Ora, parece ter sido a adoção dessa política de fortalecimento das organizações da sociedade civil e, com ela, a potencialização do mercado e de seus princípios na busca da eficiência da máquina estatal, bem como a implementação de uma austeridade orçamentária e fiscal, que fez do governo Ricardo Coutinho uma referência 'positiva', exemplo de 'eficiência administrativa', segundo a ótica dos avaliadores dos institutos de pesquisa, a exemplo do Ibope, que prestam seus serviços tanto ao mercado quanto aos governos. O ambiente político de competição e ranking entre as esferas administrativas e entre governantes de uma mesma esfera, além da definição de critérios cada vez mais rigorosos no acesso a determinadas políticas oficiais, são exemplos da racionalidade gerencial e econômica vigente, a qual impacta diretamente nas políticas sociais.

\section{O privado na educação pública}

O governo da Paraíba, especialmente nos dois últimos mandatos (PSB), mostrou-se bastante afinado e 'consequente' na implementação e alcance dessa racionalidade administrativa, por um lado, e de fortalecimento da presença [direta e/ou indireta] da iniciativa privada em diferentes setores da esfera estatal. Coincidências à parte e a título de ilustração, no ano de 2016 as mesmas pesquisas realizadas pelo Ibope [publicadas no jornal Estado de São Paulo em 05/09/2016] destacavam, igualmente, além da Paraíba [1 ${ }^{\circ}$ do ranking], os governos do Piauí (PT) e do Pernambuco (PSB), dentre outros, como exemplos de que a adoção dos critérios do mercado, por parte dos governos, e a respectiva abertura à lógica das parcerias, pode resultar no alcance de eficiência na gestão pública.

Fazendo um recorte nas distintas áreas de atuação, e procurando identificar a adoção da política de privatização na área educacional pública, particularmente como tem se dado a incidência do empresariado, seja na implementação de programas, na gestão educacional ou em processos formativos nas redes públicas escolares, os dados levantados pela pesquisa realizada pelo GREPPE, com fins ao Mapeamento das estratégias de privatização da Educação Básica no Brasil - (2005-2015), permitem identificar, no estado da Paraíba, 
diferentes "parcerias" realizadas entre o governo e instituições privadas com vistas a implementação de programas específicos, cujos objetivos, abrangência, duração, vigência, etapas e público-alvo, dentre outros, procuraremos destacar a seguir.

Em primeiro lugar, quanto às instituições contratadas como "parceiras", cujos contratos estavam vigentes em 2015, identificamos as seguintes: Google, Universidade de Ciências Aplicadas da Finlândia, Instituto de Co-responsabilidade Educacional-ICE, World Fund for Education, Instituto Sonho Grande, Fundação Roberto Marinho, Instituto Ayrton Senna, Instituto Unibanco e Fundação Itaú Social, além do próprio Ministério da Educação, que atua em conjunto com a Fundação Roberto Marinho e com a Fundação Itaú Social na implementação de dois Programas com objetivos diferentes. Como se percebe, são nove instituições privadas, com perfis e setores econômicos de origem bem distintos, mas com interesses semelhantes, cujos traços identitários lhes colocam no mesmo setor do mercado que busca, na área educacional, a disputa de hegemonia, nos termos identificados por Gramsci (2000) na identificação do que chama de "sociedade civil" ou, mais precisamente, de "aparelhos privados de hegemonia".

Como algumas dessas organizações tem sua origem auto identificada no próprio nome (ex.: Fundação Itaú Social, Inst. Unibanco, Fund. Roberto Marinho, Google of Education), consideramos ser útil ao leitor uma breve identificação de outras dessas organizações, tendo em vista melhor compreensão da análise que aqui apresentamos. Por exemplo, o Instituto de Co-responsabilidade Educacional, conforme identificamos em seu próprio site, é uma entidade que se define como 'sem fins econômicos', criada desde 2003 por um grupo de empresários que buscam um novo modelo de escola com padrão de excelência; e tem, como missão, contribuir com inovações de conteúdo, método e gestão na Educação Básica brasileira. Atua junto a 16 secretarias estaduais de educação e 8 secretarias municipais, em diferentes regiões do país. Dentre as empresas que investem em suas ações, destacam-se: ItaúBBA, Instituto Natura, EMS, Jeep, Fiat-Chrysler, Trevo Tecnologia e Instituto Sonho Grande. O Instituto tem sede no estado do Pernambuco.

Já a World Fund for Education tem sede em Nova York, foi fundada em 2002 como entidade privada sem fins econômicos, que visa contribuir com a qualidade da educação pública na América Latina, notadamente no ensino de Matemática, Robótica e Ciências, oferecendo formação a professores das áreas de Física, Química, Biologia e Matemática. Através de um de seus vários Programas, o STEM Brasil, atua em 14 estados brasileiros desde 2009, oferecendo formação exclusiva a professores da Educação Básica, com duração de dois anos, com vistas a intervir nos conteúdos curriculares das áreas supracitadas, com 
destaque especial em Ciências e Matemática. Tem uma plataforma online própria e uma Comunidade de Aprendizagem Virtual (CAV), por meio das quais se desenvolvem igualmente outros Programas, tais como o LISTO, destinado à formação continuada de diretores escolares. Dentre as empresas multinacionais que compõem seu conselho diretor ou apoiam financeiramente as ações da World Fund, encontram-se: JP Morgan, HStern, Morgan Stanley, Boston Common Asset Managment, Grupo Topaz, Glovista Investments, Tenaris, W.K. Kellogg Fundation, Fundación Coppel, dentre outros.

Quanto ao Instituto Sonho Grande, trata-se de uma ONG que tem por objetivo atuar na melhoria do ensino público brasileiro, articulando outras ONGs e demais instituições privadas que atuem nessa mesma perspectiva, de modo a "impactar na Educação Básica brasileira nos próximos 15 anos", como explicita seu próprio site. Os termos parceria, escalabilidade, inovação, execução e excelência figuram dentre os valores que orientam suas ações, o que demonstra a perspectiva gerencial de busca por eficiência nos parâmetros mercadológicos.

Como se percebe a partir desses três exemplos - encontraríamos semelhanças nos objetivos e perfis de atuação das demais organizações privadas supra mencionadas - não restam dúvidas de que há uma intenção clara e uma ação organizada, planejada e focada estrategicamente na área da Educação Básica, por parte dessas organizações privadas, cujos interesses subjacentes incidem diretamente na formação de uma cultura gerencial no setor público. Trata-se, ao nosso ver, de processo político de clara disputa e construção de hegemonia, cuja legitimidade é forjada e assegurada pelo próprio Estado, na perspectiva de fortalecimento do setor privado - leia-se: mercado! - em detrimento do público.

De forma nada sutil nem sub-reptícia, dissemina-se a falsa percepção da naturalidade e irreversibilidade desse processo, visto que o aparelho estatal estaria definitivamente corroído em suas estruturas, sem perspectivas de recomposição a curto, médio ou longo prazo, ao tempo em que as demandas sociais não cessam e urgem por iniciativas governamentais. As necessidades educacionais, por exemplo, são uma constante no contexto social capitalista e de revolução tecnológica de $4^{\mathrm{a}}$ geração. Adequar a educação pública a esta nova ordem, portanto, se torna um imperativo político governamental, o que, de acordo com a retórica oficial, só se consegue em parceria com a iniciativa privada. É dessa forma que se constrói a hegemonia política do neoliberalismo, com a participação ativa das organizações privadas, cujos interesses são de conservação da ordem.

Em segundo lugar, quanto aos Programas desenvolvidos ou implementados por essas organizações privadas em "parceria" com o governo do estado da Paraíba, eles são vários e em distintas áreas, alcançando professores, alunos, equipes técnico-pedagógicas e diretores 
escolares. Para fins deste texto, destacamos apenas alguns exemplos que ajudam na compreensão da diversidade e da abrangência dessas "parcerias" e respectiva incidência do setor privado na educação pública estadual. São programas/projetos com foco nas áreas de ciências e tecnologia, de empreendedorismo, de gestão escolar, além de outros voltados para correção de fluxo escolar e distorção idade-série, como veremos a seguir.

Com a empresa Google, não há informações claras no site do governo do estado sobre o formato nem os termos com base nos quais se definiu o contrato ou "parceria". Não obstante, o Programa é o mesmo já implementado em vários países do mundo, envolvendo mais de 50 milhões de usuários, sendo o segundo maior programa da empresa, o 'Google for Education'. Só com o governo do estado de São Paulo, por exemplo, a parceria envolve 4,5 milhões de usuários. Embora não haja informação sobre o seu alcance quantitativo desse programa na Paraíba, o fato é que o governo estadual adotou o programa 'Google Sala de Aula', que foi desenvolvido para auxiliar professores a elaborar aulas mais atrativas, criar e receber tarefas sem usar papel, além de outras iniciativas. Foi o primeiro estado da região Nordeste a firmar "parceria" com a Google, para que alunos, professores e funcionários da rede estadual de ensino tenham acesso a um conjunto de ferramentas para utilização no processo ensino-aprendizagem. Objetiva-se, com o programa, fazer com que os alunos usem, com mais intensidade e frequência, ferramentas online no processo de aprendizagem, inclusive criando e interagindo com professores e colegas. O programa está em vigência desde 2015, sem informações de data limite para seu encerramento.

Com a Universidade de Ciências Aplicadas da Finlândia, a parceria foi celebrada desde 2015, e consiste em promover intercâmbios de experiências dos alunos de Ensino Médio da rede estadual de ensino em Universidades daquele país, por períodos de três meses, com objetivo central de, após o intercâmbio, se promover a aplicação de conhecimentos e projetos de empreendedorismo e de ensino de Ciências e Matemática nas escolas estaduais paraibanas. Os recursos investidos, a seleção do público-alvo (professores e alunos do Ensino Médio) e as providências burocráticas para a realização dos intercâmbios são de responsabilidade do governo da Paraíba.

Outro Programa que destacamos é 'Prêmio Gestão Escolar', criado desde 1998 pelo Conselho Nacional de Secretários de Educação (Consed), em parceria com entidades que apoiam o fomento da educação no Brasil. Voltado para gestores/diretores escolares, seu objetivo é valorizar e motivar escolas públicas no desenvolvimento de uma gestão democrática e de qualidade. Ao longo da trajetória de sua implementação, o Prêmio já envolveu 34.832 instituições no país. Embora não haja informação clara sobre o ano de início 
da "parceria" com o Instituto Unibanco, organização 'parceira' na implementação do programa junto ao governo da Paraíba, o fato é que ele já estava em vigência no ano de 2015, período limite da coleta de dados/mapeamento feito pelo GREPPE.

Também merecem destaque dois projetos de natureza pedagógica, voltados para a correção da distorção idade-série: o 'Caminhando' e o 'Alumbrar', ambos concebidos e implementados pela Fundação Roberto Marinho, por meio de contrato com o governo da Paraíba. O primeiro, voltado para crianças de 13 a 17 anos, tem como público-alvo estudantes e professores das escolas estaduais; e o segundo, direcionado para alunos apenas do Ensino Fundamental, de modo a lhes assegurar o ingresso no Ensino Médio no tempo adequado, conta com apoio e parceria do Ministério da Educação em sua implementação. Este último (Alumbrar) está presente nas 14 Gerências Regionais de Ensino desde 2014, envolvendo a participação de 7.604 alunos. A metodologia fundamental é a telessala, seguindo a mesma lógica dos telecursos da Fundação Roberto Marinho.

Finalmente, destacamos o Programa chamado "Escola Cidadã Integral”, implantado pelo governo estadual em parceria com o Instituto de Co-Responsabilidade Educacional, o WorldFund e o Instituto Sonho Grande no ano de 2015. Trata-se de um projeto-piloto no âmbito estadual, que transformou algumas escolas de Ensino Médio da rede estadual de ensino em 'Escolas Cidadãs Integrais', que passaram a funcionar em tempo integral, com objetivo de formar indivíduos protagonistas, agentes sociais e produtivos, com conhecimentos, valores e competências dirigidas ao pleno desenvolvimento social e preparo para o exercício da cidadania. De acordo com o Programa, essas escolas têm conteúdo pedagógico, método didático e administrativo próprios, com projeto pedagógico cujas metas devem ser perseguidas pelos profissionais que nela atuarem. Não há clareza de informação sobre a responsabilidade pela concepção desse Programa nem as contrapartidas oferecidas pelo governo do estado às referidas instituições parceiras.

Todavia, o que chama a atenção é que o Escola Cidadã Integral tornou-se política oficial, instituída pelo governo do estado por meio de Medida Provisória $n^{\circ}$ 267, de 07 de fevereiro de 2018, publicada no Diário Oficial do Estado no 16.555 , do dia 09 do mesmo mês. Com esta medida, o governo Ricardo Coutinho elaborou uma das principais propagandas no último período eleitoral, apresentando-a como uma das maiores conquistas que a população do estado poderia ter alcançado nos últimos anos, prometendo a quantidade de 52 unidades escolares até o final do mandato (31/12/2018). Apesar de ousada a iniciativa no que diz respeito a sua abrangência e ao curto espaço de tempo para implementação de suas metas, e mesmo que as providências administrativas já estejam em curso para que em 2019 os três 
perfis de Escolas Cidadãs Integrais estejam funcionando [Escolas Cidadãs Integrais-ECI, Escolas Cidadãs Integrais Técnicas-ECIT e Escolas Cidadãs Integrais SocioeducativasECIS], o texto da Medida Provisória deixa claro que ela dependerá da disponibilidade orçamentária do estado.

Chama a atenção, porém, para fins desta análise, a brecha legal definida na Medida Provisória para que o governo recorra à estratégia das parcerias com vistas à implementação do respectivo Programa, conforme o texto seguinte:

Art. 22. O Programa de Educação Integral será executado com recursos do orçamento estadual e programas federais, sem prejuízo de captação de recursos de outras fontes.

Art. 23. A Secretaria de Estado da Educação poderá firmar convênios, termos de parceria ou cooperação e instrumentos congêneres para executar ações em favor das Escolas Cidadãs Integrais, Escolas Cidadãs Integrais Técnicas e Escolas Cidadãs Integrais Socioeducativas. (PARAÍBA, D.O.E. de 09.02.2018, p. 3. Grifos nossos)

Ora, considerando que o Programa está implantado e desenvolvido em unidades escolares da Rede Pública Estadual (prédios existentes e outros novos), atendendo ao Ensino Fundamental II integral, Ensino Médio integral, Ensino Médio Profissionalizante integral e Socioeducação integral (Educação de Jovens e Adultos), e que essa implantação gerará uma diversificação pedagógica no interior da rede de tal modo a poder despertar expectativa de sua ampliação para o conjunto das escolas de nível médio, por exemplo, isso sugere algumas hipóteses sobre o que poderá ocorrer num futuro próximo, ao longo da próxima gestão governamental (2019-2022), cujo candidato foi eleito pelo mesmo partido do atual governador (PSB), seu principal cabo eleitoral e mentor das principais estratégias da campanha eleitoral e do programa governamental.

Neste sentido, temos como hipóteses iniciais duas possibilidades a serem aferidas com o desenvolvimento da política: a) que o eventual sucesso desse Programa poderá servir como moeda de disputa e consolidação política do grupo/projeto governante, na medida em que poderá convencer ou suscitar interesses de prefeituras para que em seus municípios e/ou microrregiões do estado também sejam implantadas Escolas Integrais, de modo que estas poderão se tornar o parâmetro maior da política educacional e da atuação do governo estadual nos próximos anos; b) que este Programa faz parte de uma estratégia maior de introjeção e enraizamento da racionalidade gerencial na rede estadual de ensino, ao tempo em que se garantira a adequação dos conteúdos formativos às demandas do processo produtivo, seja em escala nacional/regional, buscando-se elevar o nível médio de formação da mão de obra das novas gerações, por um lado e, por outro, buscando com mais eficácia o alcance das metas do IDEB e do IDEPB. Ou ainda, mas não de forma excludente, oferecendo uma formação 
técnica que se adeque os arranjos produtivos locais, contribuindo para a dinamização e mobilidade social.

A elaboração dessas hipóteses está pautada na compreensão de que os objetivos de atuação das organizações privadas que atuaram como "parceiras” na implementação do Programa desde 2015, são de infundir seu ideário de gestão e de formação ideológica na máquina estatal, principalmente nas escolas públicas, por onde os processos de construção hegemônica junto às novas gerações tem maior potencial. Além disso, considerando a possibilidade dessas organizações [Instituto de CoResponsabilidade Educacional, WorldFund e Instituto Sonho Grande] terem participado da concepção do Programa, bem como das possibilidades legais e do ambiente político favorável à continuidade da mesma estratégia político-administrativa, por parte do governador eleito (PSB), em termos de fortalecimento da iniciativa privada, de eficiência gerencial e equilíbrio fiscal, não só as parcerias previstas no Art. 23 da supracitada Medida Provisória nº 267/2018 serão firmadas, como também os referenciais de eficiência, de controle de metas e de resultados serão os parâmetros de gestão a serem adotados nas Escolas Cidadãs Integrais, inicialmente, e cobrados pelo governo de turno para os seus respectivos gestores. Posterior e gradativamente, a depender dos resultados alcançados, esses mesmos parâmetros serão implantados em toda a rede estadual de ensino da Paraíba, independente da etapa ou do nível de escolarização. Aliás, como se observa no texto baixo, a própria Medida Provisória nº 267 já define que:

Art. 13. [...] a permanência do Professor, Diretor, Coordenador Administrativo-Financeiro, Coordenador Pedagógico das ECI, ECIT e ECIS está condicionada aos seguintes fatores: I - aprovação em avaliações de desempenho aplicadas de acordo com critérios a serem estabelecidos pela Secretaria de Estado da Educação; II - atendimento das condições estabelecidas neste instrumento e em legislação correlata à sua atuação profissional; III - cumprimento das bases pedagógicas e de gestão das ECI, ECIT e ECIS; [...]

$\S 1^{\circ}$ A análise dos termos do inciso I, II, III, IV do caput deste artigo pressupõe avaliação prévia, podendo-se ocorrer a qualquer período, não havendo prazo de permanência dos servidores nas referidas funções.

$\S 2^{\circ}$ A critério da Administração, em decorrência de inadequação, irregularidade funcional ou insuficiência de desempenho no âmbito das ECI, ECIT e ECIS, os Professores serão removidos, e os Diretores, Coordenador Pedagógico e Coordenador Administrativo-Financeiro serão exonerados de seus cargos comissionados.

Art. 14. As metas e os objetivos das escolas, constantes no Plano de Ação das mesmas, sejam individuais ou coletivos, deverão ser aprovados pela Secretaria de Estado da Educação, que também deverá estipular os critérios em que serão avaliados os resultados. (PARAÍBA, D.O.E. de 09.02.2018, p. 3. Grifos nossos)

Em nossa compreensão, a criação desse Programa como política oficial do estado também se constitui em estratégia facilitadora de implantação das diretrizes estabelecidas na 
nova Base Nacional Curricular Comum, estreitando ainda mais os laços entre a política educacional do governo estadual e a política nacional. Com esta perspectiva, o governo do estado abre condições políticas e legais para buscar apoio/convênios junto ao Ministério da Educação, ainda que não tenha sido aliado ou apoiador do candidato que venceu as eleições presidenciais no último pleito. Não por acaso figura, dentre os membros da equipe responsável pela implantação do Programa Escola Cidadã Integral, instituída por Portaria do governo estadual, uma das responsáveis pela articulação institucional, indicada pelo MEC, para viabilização da implantação da BNCC junto a governos estaduais e municipais. Esta mesma pessoa foi nomeada pelo governo da Paraíba (Ato Governamental $\mathrm{n}^{\circ} 1.898$, publicado no D.O.E. $\mathrm{n}^{\mathrm{o}}$ 16.414, de 01.07.2017) como cargo comissionado para atuar como assistente de Gabinete da Secretaria Estadual de Educação.

Por essas e outras, as ações governamentais vão corroborando as análises segundo as quais está em curso um processo acelerado não apenas de consolidação da racionalidade gerencialista na gestão pública estatal, mas, da mesma forma e intensidade, o enraizamento da perspectiva privatista no trato com a coisa pública, haja vista a generalizada e desenfreada busca por um padrão de eficiência que tem alto custo social. O tempo e a dinâmica histórica se encarregarão por suscitar maiores evidências.

\section{REFERÊNCIAS}

ABRUCIO, F. L. Trajetória recente da gestão pública brasileira: um balanço crítico e a renovação da agenda de reformas. Revista de Administração Pública, v. 41, p. 67-86, 2007.

BRASIL. Lei no 11.079, de 30 de dezembro de 2004. Institui normas gerais para licitação e contratação de parceria público-privada no âmbito da administração pública. Brasília: Congresso Nacional, 2004. Disponível em: http://www.planalto.gov.br/ccivil_03/_ato20042006/2004/lei/111079.htm. Acesso em: 10 dez. 2018.

DE ANGELIS, Cristiano T. A Emergência da Reforma do Estado brasileiro: a governança compartilhada e o modelo do novo serviço público. Revista Planejamento e Políticas Públicas, Brasília: IPEA, n. 45, jul./dez. 2015.

GRAMSCI, A. Maquiavel, a Política e o Estado Moderno. 6. ed. Rio de Janeiro: Civilização Brasileira, 1988.

GRAMSCI, A. Cadernos do cárcere. Rio de Janeiro: Civilização Brasileira, 2000. v. 3.

PARAÍBA. Governo Estadual. Lei n ${ }^{\circ}$ 8.043/2006. Institui o Plano Estadual de Educação. Anexo. Diário Oficial do Estado, n. 13.264, de 01 de julho de 2006. 
PARAÍBA. Governo Estadual. Lei n⿳ 8.486/2008. Cria o Fundo de modernização do Poder Legislativo da Paraíba e dá outras providências. João Pessoa: Assembleia Legislativa, 2008. Disponível em: http://www.al.pb.leg.br/leis-estaduais. Acesso em: 10 dez. 2018.

PARAÍBA. Governo Estadual. Medida Provisória n. 276, de 07 de fevereiro de 2018. Cria o Programa de Educação Integral, composto por Escolas Cidadãs Integrais - ECI, Escolas Cidadãs Integrais Técnicas - ECIT e Escolas Cidadãs Integrais Socioeducativas - ECIS e institui o Regime de Dedicação Docente Integral - RDDI e dá outras providências. Diário Oficial do Estado n⿳ 16.555, do dia 09.02.2018.

PEREIRA, L. C. B. A reforma do estado dos anos 90: lógica e mecanismos de controle. Brasília: Mare, 1997.

\section{Como referenciar:}

SOUZA, Antônio Lisboa Leitão de. Políticas governamentais para a educação básica na Paraíba: a privatização como estratégia de hegemonia. Revista on line de Política e Gestão Educacional, Araraquara, v. 22, n. esp. 3, p. 1340-1354, dez., 2018 ISSN: 1519-9029. DOI: 10.22633/rpge.v22iesp3.12017

Submetido em: 10/10/2018

Aprovado em: 16/11/2018 